\title{
CONTINUIDAD Y CAMBIO EN LA POLITICA VASCA: NOTAS SOBRE IDENTIDADES SOCIALES Y CULTURA POLITICA
}

Francisco José Llera

Universidad del País Vasco, Bilbao

RESUMEN. Son muy escasos en nuestro país los estudios sobre cultura e identidad políticas, y la mayoría de los existentes han sido publicados fuera de nuestras fronteras. Por ser uno de los campos más fructíferos de la Ciencia y la Sociología Políticas contemporáneas, parece pertinente la apcrtura de esta línea de investigación para una mejor comprensión del proceso de consolidación democrática y, particularmente, del pluralismo polarizado vasco. A partir de una metodología muestral se estudian las características de la segmentación política, por un lado, y los soportes de la violencia política, por otro.

Está por hacer un estudio sistemático de la producción y articulación de las identidades sociales en la vida política vasca, al igual que carecemos de una visión comprehensiva y empírica de los contenidos de nuestra cultura política, por citar algunas de las enormes lagunas existentes en la reflexión de la ciencia y la sociología políticas sobre la realidad vasca.

Las reflexiones que se aportan en estas páginas tratan, por una parte, de introducirnos en esta perspectiva y, de otra, sistematizar la no poca, aunque fragmentaria, información de campo acumulada durante estos años, con el fin de abrir nuevas vías de análisis y diagnóstico.

Es importante subrayar que somos conscientes de que la manera de producirse la política en el País Vasco no es ni única, ni original, en nuestro entorno occidental, aunque muestre algunos indicadores peculiares, propios de su específica textura subcultural. Este punto de partida nos plantea el reto de abrir nuestros análisis a planteamientos más comparativos, en los que lo 
macro y lo microanalítico se compensen adecuadamente. No ha sido posible operacionalizar esta perspectiva en estas notas, aunque hayamos apuntado referencias críticas en tal sentido.

He seleccionado un puñado de indicadores de los muchos disponibles y los he ordenado de una forma absolutamente discutible. Creo que lo importante es abrir un debate sobre cómo abordar sistemáticamente el estudio de las identidades sociales y la cultura política en nuestras respectivas áreas de aplicación.

El sentido de una tal selección y ordenación lo da aquello que parece ser más relevante para los actores sociales en el actual escenario de la vida política vasca, siendo, además, lo que parece discriminar con más fuerza las supuestas subculturas partidarias.

Así, pues, tras una breve introducción conceptual que puede servir de marco para la reflexión, nos centraremos en dos grandes apartados, como son: las características de la segmentación política y los soportes de la violencia política.

Quizá una de las perspectivas abiertas, o hipótesis a madurar, es que se apuntan indicios de que el pluralismo político de la sociedad vasca se abre camino, a duras penas, hacia pautas de una mayor permeabilidad, a costa de un consenso básico sobre la desactivación de la violencia. Tales pautas podrían acercarse a la definición de la «cultura cívica».

\section{NOTAS INTRODUCTORIAS}

En este apartado voy a comenzar definiendo y operacionalizando algunos de los conceptos y dimensiones políticas sobre los que girará el análisis posterior de los datos referidos a la realidad vasca. Los que considero más centrales para el momento actual son, entre otros: la definición de las identidades sociales de los electorados, las características y tipificación de la cultura política, las dificultades para definir la base del consenso político y, por contra el arraigo de la política de adversarios.

\subsection{Identidades sociales}

Las identidades sociales pueden ser estudiadas desde la perspectiva sicosocial de los factores cognitivos y afectivos que ligan a los individuos con las colectividades y, a partir de ahí, con las actitudes y el comportamiento políticos, o bien desde los precondicionamientos socioeconómicos y organizacionales de la acción colectiva ${ }^{1}$.

1 Una aplicación ecléctica al caso español la hacen S. H. Barnes, P. McDonough y A. López PINA, «The development of partisanship in new democracies: the case of Spain», 
En el caso vasco parece que el potencial de la movilización política se presenta principalmente motivado por variables normativas ligadas al discurso político del nacionalismo.

La construcción de las identidades sociales es algo relacional que se sustenta en una polarización latente, aunque las distancias percibidas entre grupos opuestos no tienen por qué ser simétricas. Este distanciamiento diferencial indica que la polarización podría no ser compartida por los presuntos antagonistas, agudizándose el sentido de la oposición y de la hostilidad más en un polo que en otro.

\subsection{Cultura política}

Desde que Almond y Verba ${ }^{2}$ definieran la cultura política como «patrones de orientación» hacia objetos políticos, que establecen modelos probabilísticos, se ha desarrollado un amplio campo de investigación. Por una parte, las orientaciones son predisposiciones para la acción política y están determinadas por factores tales como la tradición, la memoria histórica, las motivaciones, el sistema normativo, las emociones y los símbolos, que podemos agrupar en tres grandes tipos: cognitivas, afectivas y valorativas.

Sin embargo, no se puede obviar ni la relación entre la cultura política y la estructura del escenario político. ni el condicionamiento histórico, socioestructural o experimental de las creencias, emociones y valores políticos.

De la combinación de sus dimensiones de orientación política ellos deducen su tipología pura («localista», «de súbdito» y «participante») o mixta («localista-de súbdito», «de súbdito-participante» y «localista-participante»), a partir de cuyo contraste plantean su tesis de que la cultura política congruente con una democracia estable debería ser una mixtura en la que se combinen equilibradamente actividad y pasividad, obligación y compromiso, consenso y tensión.

Así es cómo ellos llegan a su útima categoría mixta de cultura política, la «cultura cívica», que define a un ciudadano potencialmente activo, relativamente interesado en la vida política, con un alto nivel asociativo extrapolítico $y$, sobre todo, con un sentimiento de que puede influir sobre el sistema político y de que éste es sensible a sus demandas.

Los indicadores de una tal operacionalización son:

en American Journal of Political Science, 29 (1985), pp. 695.720; y de los mismos autores, "Social identity and mass politics in Spain», en Comparative Political Situdies, vol. 21, núm. 2 (1988), pp. 200-230.

"G. A. Almond y S. Verba (eds.), The Civic Culture: political ottitudes and democracy in five nations, Princeton, NJ: Princeton Univ. Press, 1963, y The Civic Culture Revisited: un analytical Siudy, Boston, Mass.: Little Brown, 1980. 
1. La percepción de una mayor o menor probabilidad de influencia sobre la política entre el nivel local y el nacional.

2. La mayor o menor utilidad de la acción asociada con grupos informales o con partidos políticos.

3. La actividad política y el contacto con las comunicaciones políticas a través de los mass media.

4. La pertenencia a organizaciones voluntarias y a organizaciones políticas.

5. El nivel educativo.

6. La congruencia entre las experiencias con autoridad en la familia, la escuela y el trabajo en el contexto del proceso de socialización.

\subsection{El consenso}

El carácter normativo de la reflexión científica sobre la cultura política se asienta, a su vez, en un viejo principio propugnado por la racionalidad ilustrada, como es el del consenso sobre valores y normas. Para Eckstein, siguiendo a Almond y Verba, la condición de estabilidad de las democracias fuertemente competitivas es la existencia de un sentimiento de «solidaridad superior y muy general» ${ }^{3}$. El que tal cohesión refuerce centrípetamente la estabilidad política o dispare la segmentación de lealtades subculturales depende:

1. De la estructura social.

2. De un sentido de la nacionalidad cristalizado.

3. De las interconexiones sociales.

4. Y, sobre todo, de la congruencia de los patrones de autoridad gubernamentales o no ${ }^{4}$.

Este último aspecto es el que absorbe su atención al contrastar que una tal congruencia no puede ser perfecta, ni deseable, sino que se observan disparidades variables en función de las tensiones producidas por expectativas ambivalentes, que surgen de sistemas normativos distintos o incluso antagónicos y de los comportamientos anómicos de quienes carecen de orientación normativa para su acción.

${ }^{3}$ H. Eckstein, Division and Cohesion in Democracy, Princeton, NJ: Princeton University Press, 1966, p. 76.

${ }^{4}$ Su modelo se puede ver en ibid., p. 182. 


\subsection{La política de adversarios}

Aunque Finer ${ }^{5}$ acuñara en el año 70 el término adversary politics para referirse a una situación, en la que la competición electoral en un sistema básicamente bipartidista (el británico) produce una polarización extrema de programas, discursos y estilos de gobierno, el desarrollo posterior ${ }^{6}$ de esta idea permite su aplicación a situaciones pluripartidistas y no sólo a nivel estatonacional.

Algunas de las características definidas son las siguientes:

1. El mecanismo de votación protege a los grandes partidos establecidos frente a la amenaza de nuevos competidores.

2. Los partidos son controlados por ideólogos activistas, menos inclinados a la popularidad electoral o a los compromisos sobre principios ideológicos en orden a ganar votos (esto se da con mayor probabilidad en los partidos de masas que en los de cuadros) que la preocupación por ganar de los líderes de partido, los parlamentarios o los grupos de interés que les respaldan.

3. Los partidos adoptan posiciones políticas más polarizadas que la mayoría de sus votantes, obligando a los electores a votar por «el menos malo» y borrando del horizonte político la oportunidad de votar por políticas consensuales.

4. Finalmente, cuando llegan al gobierno tratan de arrasar con la legislación anterior, creando un clima de incertidumbre política, especialmente en lo que se refiere a la política económica ${ }^{7}$ en los sistemas políticos establecidos, o a las políticas de mayor significación institucional en los sistemas en construcción.

\section{EUSKADI: ENTRE LA SEGMENTACION Y EL CONSENSO}

Han pasado más de diez años desde el comienzo de la transición política y aún hay indicios racionales para dudar que ésta puede darse por cerrada en el País Vasco. No es tanto la persistencia de la violencia política cuanto el escenario en el que ésta se produce y, sobre todo, la cultura política en la que arraiga su reproducción.

Los partidos son los actores principales del juego político; sin embargo,

S. A. Finer (ed.), Adversary Politics and Electoral Reform, Londres: Wigram, 1975; del mismo autor, The Changing British Party System 1945-1979, Washington, DC: American Enterprise Institute, 1980.

${ }^{6}$ P. J. Dunleavy y C. Husbands, British Democracy at the Crossronds: votings and party competition in the 1980s, Londres: Allen \& Unwin, 1985, caps. 2-4.

7 A. M. Gamble y S. A. WalkLand, The British Political System and Economic Po. licy 1945-83: studies in adversary politics, Oxford: Oxford Univ. Press, 1984. 
en Euskadi tienen que compartir escena con los terroristas y su red social, con la Iglesia en sus variadas versiones y con el protagonismo de la calle como espacio de intervención política cotidiana.

La fragilidad del sistema de partidos vascos es evidente a poco que se eche una mirada retrospectiva a lo ocurrido desde el comienzo de la transición.

El clima de movilización política permanente ${ }^{8} \mathrm{y}$ las tensiones cruzadas, vividas con radicalidad emocional por buena parte de los ciudadanos, han jalonado de fraccionalismo, inestabilidad, polarización y ausencia de horizonte la vida política vasca de esta década poco prodigiosa.

Con todo, se pueden distinguir tres grandes períodos tal como desarrollo en otro lugar ${ }^{9}$, así: el primero, que va de 1977 a 1979, vendrá definido por la organización fragmentaria del nacionalismo, el debate constitucional y la política de pactos en torno al proceso autonómico; el segundo, entre 1979 y 1984, es el de la construcción autonómica bajo la hegemonía nacionalista y el predominio del PNV gracias a la instrumentalización del abstencionismo institucional de HB y del terrorismo; el tercero, entre 1986 y 1989, se caracteriza por la crisis nacionalista y la vuelta a la política de pactos, que se concreta en los gobiernos de coalición a todos los niveles y, sobre todo, en el cambio producido en el clima político tras el llamado «acuerdo por la paz» firmado en Ajuria Enea en enero de 1988 por todos los partidos políticos presentes en el Parlamento Vasco.

El año 1986 puede pasar a la historia política de Euskadi por ser un momento crucial y punto de no retorno en la crítica transición por la que atraviesa el sistema institucional vasco, cuyo síntoma es la falta de delimitación precisa en la composición, perfil electoral y distribución ideológica del sistema de partidos. Lo que ciertamente parece apuntarse en esta encrucijada es el agotamiento de un modo de hacer política cuyo paradigma es el de la adversary politics, caracterizado en nuestro caso por la maximización del conflicto; la confrontación permanente, el exclusivismo primordialista y la imposición de mayorías monocolares artificiales.

Sin embargo, el giro que están dando los acontecimientos nos lleva a pensar que va adquiriendo progresiva evidencia social, al menos entre los dirigentes políticos, la necesidad de que se abran camino las pautas políticas de una vía de pactos y acuerdos múltiples, o «consociacional» ${ }^{10}$, a medio ca-

\& Este aspecto ya lo rcsaltaban S. M. Lipset y S. Rokkan al hablar de los Cleavages in Fully Mobilized Polities, propias de los movimientos nacionalistas y de los Estados con problemas de integración y de construcción nacional, en «Cleavage Structures, Party Systems, and Voter Alignments: an introduction», en S. M. LIPSET y S. RoKkan (eds.), Party Systems and Voter Alignments: Cross-National Perspectives, Nueva York: Free Press, 1967, pp. $23-26$.

'F. J. Llera, «Continuidad y cambio en el sistema de partidos vascos: 1977-1987», en Revista de Estudios Polílicos, núm. 59 (1988), pp. 289-302.

${ }_{10}$ Esta es la reclamación de J. L.INZ en las conclusiones de su Conflicto en Euskadi, Madrid: Espasa-Calpe, 1986, p. 674. 
mino entre los modelos centrípeto y centrífugo de que habla A. Lijphart ", reconduciéndose la anterior situación de fragmentación y polarización extremas.

\subsection{El pluralismo polarizado}

En pocos temas hay tanta unanimidad como en la calificación del sistema de partidos vasco como «pluralismo polarizado», siguiendo la terminología de G. Sartori ${ }^{12}$. Esto es la tipificación que vengo sosteniendo en todos mis trabajos ${ }^{13}$, pero es también lo que han apuntado para las primeras fases J. Linz ${ }^{14}$ y R. Gunther y otros ${ }^{15}$ en los suyos.

Con una media de siete partidos parlamentarios relevantes, un índice de fragmentación parlamentaria en torno al .80 , un partido antisistema, que pugna por ocupar la segunda posición con casi un 20 por 100 de los votos válidos (fuerte presencia local con casi 600 concejales) desde el apoyo indisimulado a la estrategia violenta y un fuerte distanciamiento ideológico, no se podría caracterizar de otro modo un tal sistema de partidos.

La fragmentación no sería especialmente relevante si no llevase parejo un distanciamiento ideológico entre los partidos extremos que cuentan ${ }^{16}$, que afectan a su espacio de competición y que, además, admite distintos grados y vías ${ }^{17}$, estando afectado por la contrapuesta concepciớn del sistema social la aceptación o rechazo de las instituciones políticas o la confrontación de identidades y sistemas simbólicos, entre otros.

Veamos, pues, a continuación las dimensiones principales del distancia-

"La distinción la explica A. LijpharT en «Typologies of Democratic Systems», en Comparative Political Studies, 1: 1 (1968), p. 38, y, posteriormente, en Democracy in Plural Societies, New Haven, Conn.: Yale Univ. Press, 1977, pp. 105 y ss.

${ }_{12}$ G. Sartori, Partidos y sistemas de partidos, Madrid: Alianza, pp. 165 y ss. No podemos entrar aquí en las correcciones introducidas por P. H. MerkL (ed.), en Western European Party System (Nueva York: Free Press, 1980, pp. 6-10), ni en las matizaciones más recientes de C. VON BEYME, en Los partidos políticos en las democracias occidentales (Madrid: CIS, 1986, pp. 332 y ss.), cuando, por un lado, ve difícil la distinción entre «pluralismo moderado» y «pluralismo polarizado» $y$, por otro, aconseja la subdivisión del segundo.

${ }_{13}$ Véase F. Llera, «Continuidad y cambio en el sistema de partidos vascos: 1977. 1987», en Revista de Estudios Políticos, núm. 59 (1988), pp. 277-375.

${ }_{14} \mathrm{~J}$. Linz dice que el sistema de partidos vasco es un ejemplo del tipo que G. Sartori ha descrito como sistema multipartidista centrífugo polarizado», en Conflicto..., op. cit., pp. $317 \mathrm{y}$ ss.

${ }_{15}$ R. Gunther y otros, refiriéndose a las elecciones generales de 1977 y 1979, sostienen que «en el País Vasco el sistema de partidos ha devenido fragmentado y polarizado de forma creciente», en Spain after Franco, Berkeley: Univ. of California Press, 1986, p. 312 .

${ }_{16}$ G. SARTori, «European political parties», en J. Lapalombara y M. Weiner (eds.), Political parties and political development, Princeton: Princeton Univ. Press, 1966, pp. 137-176.

${ }_{17}$ G. Sani y R. Gunther, «Polarization, Fragmentation and Competition in Western Democracies», en H. DaAlder y P. MaIR (eds.), Western European Party Systems: Continuity and Change, Beverly Hills, Cal.: Sage, 1983, p. 316. 
miento ideológico y el espacio de competición entre los partidos vascos centrado en el autoposicionamiento del electorado en las escalas de izquierda/ derecha ${ }^{18}$ e independentismo/centralismo ${ }^{11}$, que condensan las identidades de clase y nacionalista, respectivamente.

Si observamos el espacio político de competencia entre los partidos políticos relevantes, delimitado por las dos dimensiones estudiadas -espacio en el que se plantea la lucha entre ellos por el voto y, por tanto, la estrategia electoral de los diferentes partidos (gráfico 1)-, y lo comparamos con los estudiados por J. Linz para 1977, 1979 y 1980, vemos que se mantiene la complejidad del sistema y que sigue habiendo distancias que dificultan la posibilidad de acuerdos, pero se ha producido un cierto reagrupamiento en

\section{GRAFICO 1}

Posicionamiento de los distintos partidos en el espacio engendrado por las dimensiones izquierda/derecha y nacionalismo en las elecciones autonómicas de 1986 en la CAV

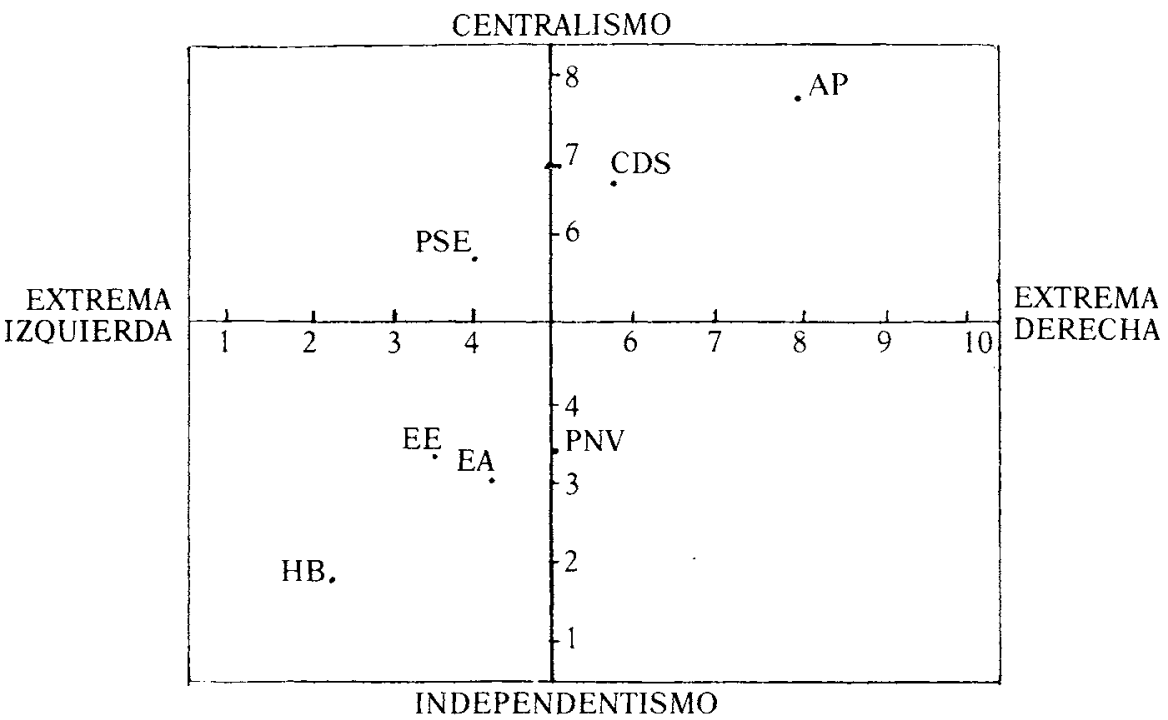

FUENTE: F. J. Llera, IPV 87.

i8 Véase R. Inglehart y H. D. Klingeman, «Party identification, ideological preference and the left-right dimension among Western mass publics», en I. BudGE y otros (eds.), Party identification and beyond, Londres: Wiley, 1976 , pp. 248 y ss.; también, J. LapoN$\mathrm{CE}$, Left and right. The topography of political perceptions, Toronto: Univ. of Toronto Press, 1981, y G. SANI y G. SARTORI, «Polarization...», op. cit., pp. 310 y ss.

${ }^{19}$ Se puede ver, en este sentido, el trabajo de A. Lijphart, «Language, Religion, Class and Party Choice: Belgium, Canada, Switzerland and South Africa compared», en R. Rose (ed.), Electoral Participation, Londres: Sage, 1980, pp. 283-327. 
el centro-izquierda y el nacionalismo moderado, a la vez que se acentúan las distancias y el aislamiento respectivo de $\mathrm{HB}$ y $\mathrm{AP}^{20}$; es obvio que el protagonismo del nacionalismo en unas elecciones autonómicas y la crisis del PNV han hecho que esta dimensión haya definido la capacidad máxima del voto nacionalista; por otro lado, el reagrupamiento producido parece augurar una mayor inestabilidad en el sistema de partidos en relación a la mayor probabilidad de transferencias de votos.

Es evidente el mantenimiento de las características básicas que define el pluralismo polarizado extremo vasco, pero su inestabilidad apunta a un cambio de tendencia más centrípeta, debido a la competencia por el centro bidimensional del sistema de partidos. Igualmente, el incremento de la competitividad de la dimensión nacionalista, a pesar de, o por, la crisis del nacionalismo tradicional, ha visto ampliarse su capacidad de absorción de voto volátil.

A este respecto, hay que decir que el relativo agotamiento de la política de enfrentamiento a gran escala entre los partidos centrales del sistema, la extensión lenta, y no sin dificultades, de la política de pactos y coaliciones, la profundidad de la crisis económico-social, ia toma de conciencia de los retos inexorables de la revolución tecnológica y la integración europea, así como la capacidad de impugnación desligitimadora del bloque antisistema y de la violencia política, pueden estar obligando a los principales partidos a dar un giro a su discurso hacia una mayor racionalización programática, como puede indicar la nuewa definición del espacio de competencia entre ellos.

El indicador de cercanía/distancia de los distintos electorados respecto de cada partido suele ser la forma de medir la transferibilidad del voto y su tendencia centrífuga o centrípeta, a lo que, si añadimos el estudio del rechazo de voto, tenemos la posibilidad de cuantificar los índices de polarización: aquí nos conformaremos con el primer paso.

Fijándonos en la distancia expresada por cada electorado de noviembre de 1986 con respecto a cada partido, la podemos clasificar en cuatro niveles: baja distancia, cuando menos del 40 por 100 de un electorado manifiesta estar distante o muy distante de alguno de los partidos; distancia media, entre un 40 y un 60 por 100; alta distancia, entre un 60 y un 80 por 100; y distancia extrema, cuando se supera el 80 por 100. En la tabla 1 tenemos esta clasificación.

Como se puede comprobar, la mayoría de casi todos los electorados se considera distante o muy distante del resto de los partidos, llegando a definirse una clara polarización multipolar y también un alto nivel de centrifugación entre espacios electorales relativamente contiguos.

${ }^{2 n} \mathrm{~S}$. C. Flanagan ha llegado a construir un «índice de polarización» en base a la distancia percibida, como se puede ver en «Models and Methods of Analysis», en G. A. ALmond, S. C. Finnagan y R. J. Mundt (eds.), Crisis, Choice, and Change, Boston: Little Brown, 1973, pp. 43-102 y $682-696$. 
TABLA 1

Distanciamiento mayoritario de los electorados de la CAV en 1986 respecto de cada partido ${ }^{21}$

\begin{tabular}{|c|c|c|c|c|}
\hline \multirow[b]{2}{*}{ Partidos } & \multicolumn{4}{|c|}{ DISTANCIAMIENTO } \\
\hline & Bajo & Medio & Alto & Extremo \\
\hline $\mathrm{AP} \quad \ldots \quad \ldots \quad \ldots$ & 一 & - & 一 & $\begin{array}{l}\text { CDS, EA, EE, } \\
\text { HB, PNV y } \\
\text { PSOE }\end{array}$ \\
\hline $\operatorname{CDS} \ldots \ldots \ldots \ldots$ & AP & - & $\begin{array}{l}\text { EA, PNV y } \\
\text { PSOE }\end{array}$ & $\mathrm{EE}$ y $\mathrm{HB}$ \\
\hline $\begin{array}{llllll} & E A & \ldots & \ldots & \ldots & \ldots\end{array}$ & - & $\mathrm{EE}, \mathrm{HB}$ y $\mathrm{PNV}$ & $\mathrm{AP}, \mathrm{CDS}$ y PSOE & 一 \\
\hline $\begin{array}{lllll}\mathrm{EE} & \ldots & \ldots & \ldots & \ldots\end{array}$ & EA & PNV y PSOE & $\mathrm{AP}, \mathrm{CDS}$ y $\mathrm{HB}$ & - \\
\hline $\begin{array}{llllll}\mathrm{HB} & \ldots & \ldots & \ldots & \ldots\end{array}$ & 一 & $\mathrm{EE}$ & EA y PNV & AP, CDS y PSOE \\
\hline IU/PCE .... & - & $\mathrm{EE}, \mathrm{HB}$ y $\mathrm{PSOE}$ & CDS y EA & AP y PNV \\
\hline PNV $\ldots \ldots \ldots \ldots$ & AP y EA & CDS, EE y PSOE & $\mathrm{HB}$ & 一 \\
\hline PSOE $\ldots \ldots \ldots$ & - & CDS & $\begin{array}{c}\text { AP, } \\
\text { y EA, PNV }\end{array}$ & $\mathrm{HB}$ \\
\hline
\end{tabular}

Esta situación plantea un serio problema para la cultura política de los pactos y coaiiciones, donde la combinatoria es interminable, pero con el predominio de las coaliciones entre nacionalistas (51 por 100) frente a las mixtas de nacionalistas y no nacionalistas ( 20 por 100 ), ya que la alternativa de sólo estatales ni se le plantea a la gente. Aunque la dispersión es máxima, la opción por un gobierno de frente nacional es la más apoyada (20 por 100) frente al actual gobierno de coalición PNV/PSOE (11 por 100) y a la reunificación del PNV y EA a la catalana (11 por 100).

Si la opción del frente nacional sobresale en los electorados de EA ( 34 por 100), PNV (26 por 100) y HB (25 por 100), la fórmula actual PNV/ PSOE lo hace en el del PSOE (51 por 100). Sin embargo, los del PNV prefieren la reunificación con EA ( 31 por 100), los de EA se dividen entre esa posibilidad ( 29 por 100 ) y el pacto EA/EE ( 25 por 100 ), que es el que más adeptos concita en $\mathrm{EE}$, aunque sin entusiasmo ( 35 por 100), y, finalmente, los de $\mathrm{HB}$ se dividen entre el pacto con EA (30 por 100) y con EE (20 por 100).

21 Elaboración propia a partir de un estudio dirigido por F. Llera para el Gobierno vasco en diciembre de 1987, sobre una muestra de la CAV de 1.500 entrevistas. A partir de este momento nos referiremos a este estudio como GV 87. 


\subsection{El déficit de legitimación}

La Transición política de la Dictadura a la Democracia abre un proceso de desorganización social y modernización política ${ }^{22}$ que va a encontrarse con serios problemas de arraigo social en el País Vasco: se reedita un nuevo episodio de la confrontación simbólico-política de la legitimidad de las dos violencias (la del Estado y la de los patriotas), que protagoniza los últimos ciento cincuenta años de la historia vasca, con especial virulencia en los momentos en que se intenta dar respuesta institucional a la demanda nacionalista.

La contraposición «ruptura/reforma» y el discurso político del «o todo o nada», concretan en esta coyuntura decisiva el dispositivo «imposible/ posible», que se había generado en la Dictadura.

El proceso de diferenciación racionalizadora de la esfera política que se inicia con la institucionalización democrática se encuentra con la dificultad de que una parte importante de la vida política vasca se ha autoorganizado al margen o en contra de dicho proceso institucionalizador; en definitiva, en el País Vasco se trata de una transición o contraposición entre dos tipos de politización o de esferas públicas: la generada en la movilización y en la interacción social cotidianas y la implantada en la privacidad tópica de la política de masas. En la primera, el hecho diferencial vasco es vivido y ritualizado como transgresión social con sentido y con posibilidades, mientras que la segunda se corresponde con las nuevas formas de producción de sentido en el capitalismo tardío ${ }^{23}$, que llevan consigo la despolitización y la disminución de la interacción en la vida cotidiana de la sociedad de masas.

A su vez, el conflicto de identidades/centralidades tiene un efecto también dual sobre el comportamiento político y sobre la orientación de la acción de los actores sociales. La modernización política es, además de un proceso de institucionalización, una forma de legitimación racional de los medios democráticos de consecución de objetivos colectivos. Sin embargo, aquí también se confrontan dos legitimidades y las respectivas éticas de la «convicción» y la «responsabilidad» distinguidas por $M$. Weber ${ }^{24}$.

Sin embargo, tanto la lógica del Estado como la estructura de clases de la propia sociedad vasca y su representación de intereses en una sociedad de masas, imponen que la diferenciación política tenga un impacto sobre las propias formas de expresión de lo vasco: pérdida de unanimidad nacionalista, desmovilización política de la calle, reducción de la politización cotidiana, disminución de la vida interactiva, protagonismo de los partidos polí-

${ }^{22}$ S. N. Eisenstadt, Modernización. Movimientos de protesta y cambio social, Buenos Aires: Amorrortu, 1968.

${ }^{23}$ S. Habermas, Problemas de legitimación en el capitalismo tardio, Buenos Aires: Amorrortu, 1975, p. 96.

${ }^{24}$ En «La política como vocación», en Escritos políticos, 2 vols., México: Folios, 1982, vol. II, p. 357 . 
ticos y sus rituales electorales y vivencia privada de la política como espectáculo.

Uno de los indicadores empíricos de tal déficit de legitimación es la posición de la población vasca ante la Constitución, en cuyo referéndum aprobatorio las opciones nacionalistas fueron de rechazo a través de la abstención (PNV) y del voto negativo (HB y EE, junto a AP). El resultado fue una abstención del 54,5 por 100 en la Comunidad Autónoma Vasca, un 31,3 por 100 de votos afirmativos y un 10,5 por 100 de negativos, lo que alimentó el argumento nacionalista del déficit de legitimidad en su conflicto con el gobierno central.

Casi diez años después ${ }^{25}$, el 39 por 100 ha interiorizado como obvia tal lectura del rechazo, sustentada por los electorados nacionalistas de $\mathrm{HB}$ ( 78 por 100 ), EA (53 por 100 ), EE (50 por 100 ) y PNV ( 46 por 100), mientras que no encontramos el mismo nivel de movilización en sentido contrario (14 por 100), ni siquiera entre los electorados de los partidos de ámbito estatal: AP ( 37 por 100), PSOE ( 32 por 100) y CDS (21 por 100). Con todo, el mayor contingente (47 por 100) y el más heterogéneo o no tiene una ídea clara sobre la cuestión o le resulta indiferente.

En el citado estudio GV 87, preguntados los vascos por su valoración actual de la Constitución, se dividen casi a partes iguales entre los que la consideran positiva ( 30 por 100 ), los que la juzgan como «la menos mala posible» ( 33 por 100 ) y los que la rechazan ( 26 por 100 ). Si los primeros son mayoría en los electorados de AP (74 por 100) y PSOE (70 por 100) y, en menor medida, del PNV (40 por 100), los últimos lo son en HB (63 por 100), mientras que los posibilistas alcanzan el 40 por 100 de los electorados del CDS, EE, EA y el PNV (31 por 100).

$\mathrm{Si}$ los apoyos, más o menos matizados, tienen un significado pluralista y heterogéneo, el rechazo es, predominantemente, nacionalista: el 65 por 100 se sienten nacionalistas, el 84 por 100 son nativos de la CAV, un 51 por 100 son vascoparlantes, el 49 por 100 se sienten exclusivamente vascos y otro 26 por 100 más vasco que español, siendo un 31 por 100 votantes de $\mathrm{HB}$, otro 27 por 100 de las demás opciones nacionalistas y un 23 por 100 de la abstención.

El déficit de legitimación, con todo, se puede cifrar en torno al 20 por 100 de entrevistados que valoran negativamente el cambio producido en los últimos diez años, si bien, en este caso, al no cuestionarse un objeto político susceptible de ser convertido en símbolo, el comportamiento de los electorados es mucho más heterogéneo, tal como muestra la siguiente tabla.

${ }^{25}$ Los datos proceden de un estudio sobre «La imagen de los partidos políticos en Euskadi», realizado por $F$. Llera en abril de 1987, sobre una muestra de la CAV de 1.800 entrevistas. A partir de este momento nos referiremos al mismo como IPV 87. 
Valoración de la transición política según los electorados de 1986 en la $C A V$

\begin{tabular}{|c|c|c|c|c|c|c|c|c|}
\hline & $N$ & $A P$ & CDS & PSOE & PNV & $E A$ & $E E$ & $H B$ \\
\hline $\begin{array}{lllll}\text { Positiva } & \ldots & \ldots & \ldots & \ldots\end{array}$ & 62 & 40 & 71 & 86 & 82 & 70 & 82 & 46 \\
\hline $\begin{array}{lllll}\text { Negativa } & \ldots & \ldots & \ldots & \ldots\end{array}$ & 29 & 60 & 13 & 7 & 12 & 21 & 8 & 45 \\
\hline $\begin{array}{lllllll}\text { Otros } & \ldots & \ldots & \ldots & \ldots & \ldots\end{array}$ & 9 & - & 16 & 7 & 6 & 9 & 10 & 9 \\
\hline$\% \ldots \ldots$ & 100 & 100 & 100 & 100 & 100 & 100 & 100 & 100 \\
\hline
\end{tabular}

Fuente: F. J. Llera, GV 87.

Al contrario que la Constitución, el Estatuto de Autonomía de Guernica fue aprobado en referéndum por el 53 por 100 del electorado, frente al 3 por 100 del no y el 41 por 100 de abstencionistas (entre los que se encuentran los seguidores de la consigna de HB) y se puede interpretar con J. Linz ${ }^{26}$ que enjuaga, en parte, el déficit de legitimación del referéndum constitucional.

En este sentido, los logros políticos conseguidos con el actual, aunque incompleto, proceso autonómico dividen a la población vasca en partes iguales a la hora de hacer una evaluación entre los satisfechos (28 por 100 -PSOE (56 por 100 ), CDS (55 por 100$)$, AP (52 por 100$)$ y PNV (42 por 100$)$-, los parcialmente satisfechos (31 por 100) -EA (48 por 100) y EE (43 por 100)-y los insatisfechos (26 por 100) - HB (70 por 100)-.

Parece que se puede hablar de frustración autonómica y el resultado de conjunto es un escalonamiento de las demandas autonómicas que se puede cuantificar del siguiente modo:

- Un 11 por 100 de ciudadanos conformes con lo conseguido: CDS/AP.

- Un 25 por 100 que lo estaría con la culminación del proceso de transferencias: PSOE/PNV.

- Un 31 por 100 que, tanto desde el mundo nacionalista institucional como del radical, demanda la reforma genérica del Estatuto: EA/ $\mathrm{EE} / \mathrm{HB}$.

- Un 16 por 100 que lo rechaza con mayor o menor vehemencia: HB.

- Un 1 por 100 que le parece que ha ido demasiado lejos.

- Un 16 por 100 no manifiesta una opinión al respecto.

${ }^{26}$ J. Linz, Conflicto..., op. cit., p. 672. 


\section{GRAFICO 2}

\section{Posición ante el Estatuto de Autonomía en 1987}

1. Satisfechos con el Estatuto. $(28 \%)$

2. Parcialmente satisfechos $(31 \%)$
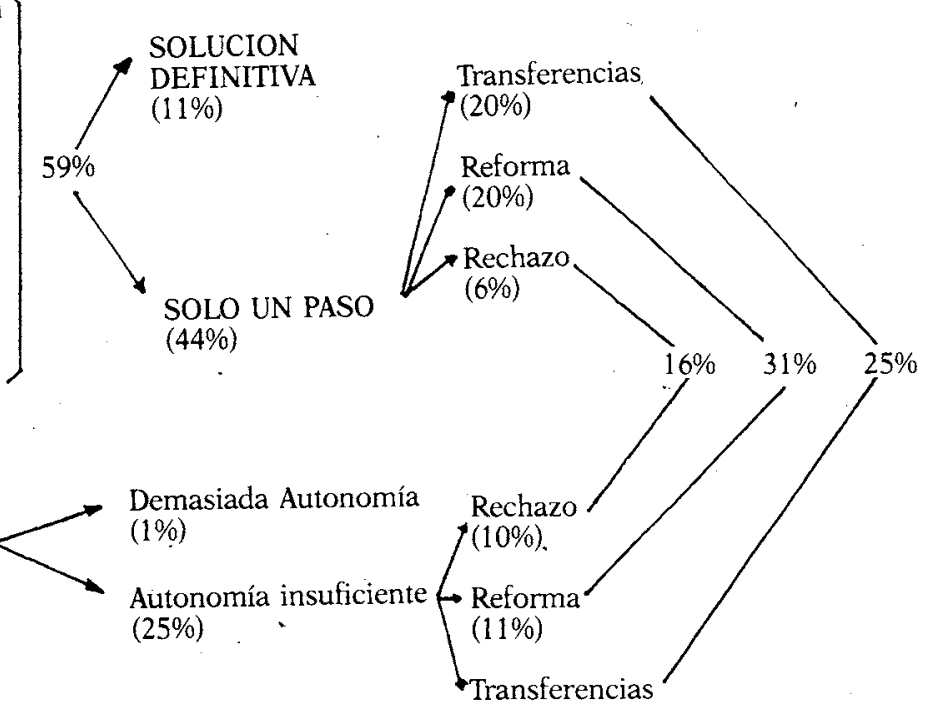

Fuente: F. J. Llera, GV 87.

$(5 \%)$

Finalmente, a pesar del rechazo genérico a lo estatal y a la interiorización de la distancia periférica respecto al centro político, es importante calibrar el modelo de organización del Estado que funciona en la opinión pública vasca y, sobre todo, comprobar su evolución desde el comienzo de la transición, como muestra la tabla 2.

\section{TABLA 2}

Evolución del modelo de organización territorial del Estado en la CAV entre 1977 y 1987

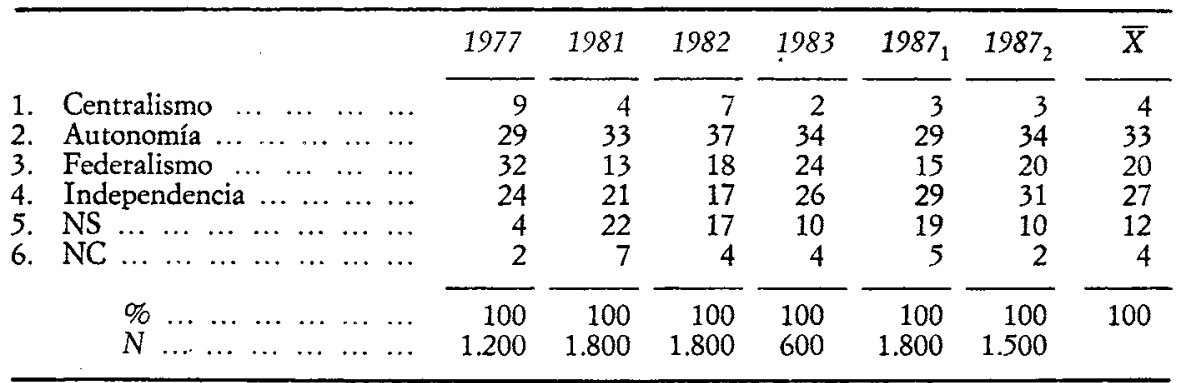

FUENTE: F. J. Llera. 
Como se puede comprobar, el centralismo, después de haber disminuido en la primera parte de la Transición, se ha estabilizado en unos niveles ínfimos ( 3 por 100), lo cual no quiere decir que las actitudes centralistas no sean más numerosas, sólo que no salen a flote por la estigmatización social que este concepto padece.

El modelo arrunómico se mantiene oscilante en torno a un tercio de ia población, recuperándose con el funcionamiento del Gobierno de coalición PNV/PSOE, tras su descenso a principios de 1987. El modelo federal, que es el que más altibajos ha padecido, se sitúa alrededor de un quinto de los entrevistados, habiéndose elevado tras la evaluación del proceso autonómico. Finalmente, el independentismo, que, con su caída continuada al compás de la institucionalización autonómica, ha vuelto a resurgir con fuerza tras la experiencia socialista de la armonización del proceso autonómico (LOAPA), se sitúa en casi un tercio de la población ( 31 por 100 ).

El modelo autonómico destaca entre los inmigrantes (55 por 100) los que se sienten sólo españoles (65 por 100) o españoles y vascos (52 por 100), no tienen ningún interés en el euskera ( 49 por 100$)$ y no se consideran nacionalistas (47 por 100); a la vez que su nivel de apoyo es relativamente mayor en los electorados de AP (79 por 100), PSOE (62 por 100), PNV (44 por $100)$, CDS (43 por 100) y los no identificados políticamente (42 por 100).

El modelo federalista destaca, entre las clases media ( 30 por 100 ) y alta (51 por 100), los que tienen estudios universitarios (39 por 100) y entre veintiséis y treinta y cinco años (25 por 100), así como los electorados de EE (41 por 100) y EA (32 por 100).

Finalmente, la independencia se incrementa entre los entrevistados nativos (40 por 100 ), los euskaldunes (48 por 100), los que se sienten sólo vascos (63 por 100) o más vascos que españoles (40 por 100$)$ y se consideran nacionalistas (48 por 100), los parados (37 por 100) y los estudiantes (40 por 100), los que tienen estudios medios (43 por 100), los menores de veinticinco años (43 por 100) y los electores de HB (78 por 100) y EA (40 por 100).

De todas formas puede ser interesante comprobar la composición política de las distintas alternativas aquí estudiadas, tal como muestra la tabla 3. 


\section{TABLA 3}

Distribución de los electorados vascos de 1986 según su opción ante el modelo de organización territorial del Estado

\begin{tabular}{|c|c|c|c|c|c|c|c|c|}
\hline & $N^{\prime}$ & $A P$ & $C D S$ & PSOE & PNV & $E A$ & $E E$ & $H B$ \\
\hline $\begin{array}{lllll}\text { Centralismo } & \ldots & \ldots & \ldots \\
\text { Autonomía } & \ldots & \ldots & \ldots & \ldots \\
\text { Federalismo } & \ldots & \ldots & \ldots \\
\text { Independencia } & \ldots & \ldots & \ldots \\
\text { NS } / N C & \ldots & \ldots & \ldots & \ldots \\
\end{array}$ & $\begin{array}{r}3 \\
34 \\
20 \\
31 \\
12\end{array}$ & $\begin{array}{r}5 \\
61 \\
33 \\
1\end{array}$ & $\begin{array}{l}18 \\
50 \\
27 \\
-5\end{array}$ & $\begin{array}{r}11 \\
62 \\
11 \\
9 \\
7\end{array}$ & $\begin{array}{r}2 \\
44 \\
14 \\
32 \\
8\end{array}$ & $\begin{array}{r}2 \\
18 \\
32 \\
39 \\
9\end{array}$ & $\begin{array}{r}1 \\
25 \\
41 \\
23 \\
10\end{array}$ & $\begin{array}{r}5 \\
12 \\
78 \\
5\end{array}$ \\
\hline$\% \begin{array}{lllllll} & \ldots & \ldots & \ldots & \ldots & \ldots\end{array}$ & 100 & 100 & 100 & 100 & 100 & 100 & 100 & 100 \\
\hline
\end{tabular}

Fuente: F. J. Llera, IPV 87.

\subsection{El conflicto simbólico}

A finales del siglo xIx, el primer nacionalismo vasco dota de fundamento discursivo a la «etnicidad» vasca, contrastando la contradictoria formulación de sus objetivos y estrategias políticas con la clarividencia en la definición de los elementos centrales del «hecho diferencial vasco»: lengua y ocupación extranjera.

La guerra civil y el franquismo dan evidencia social y generalizan la experiencia biográfica de la violencia física y de la imposible expresión de lo vasco, que convierten a la resistencia violenta frente a la Dictadura y a la transgresión social cotidiana en el actor principal de una densa y politizada vida interactiva.

Sobrevaloración de la lengua y sobredramatización del franquismo producen la movilización del unanismo vasco frente al totalitarismo al final de la Dictadura, definiendo claramente la independencia como objetivo político y generando un movimiento social de características populistas y con una fuerte capacidad de impugnación de la institucionalización política de la Democracia.

Sin embargo, la nueva situación es la de la quiebra de ese carácter unitario de lo vasco. de modo que la interiorización del conflicto da lugar a un contexto social en el que el pluralismo, base de la integración política, no puede cohabitar con una fuerte segmentación política fruto del conflicto simbólico. A la vez, tal quiebra del sistema normativo y las dificultades para la racionalización generan multiplicidad de estados anómicos, en los que está teniendo lugar la socialización de nuevas generaciones.

La sociedad vasca vive en un estado de escisión profunda en su integración social, que genera dos dinámicas a distinto plano: por un lado, la primordial contraposición de identidades colectivas, interiorizadas por los actores sociales 
como $\ll$ nosotros» $/ \ll$ ellos» ${ }^{27}$; por otro, la generación de diversidad de estados anómicos.

El primer plano, por tanto, nos indica que no hay un único universo simbólico de orientación de la acción con una evidencia social compartida, sino que hay una contraposición entre dliferentes centralidades con relevancia biográfica y cotidiana.

Con todo, el mundo nacionalista construirá su subcultura política y su discurso sobre la identidad en términos de comunidad como constructo simbólico, que sólo existe en la mente de sus miembros y que no es susceptible de descripción objetiva, sino sólo de interpretación ${ }^{28}$. Efectivamente, el PNV es el receptáculo del "capital simbólico» ${ }^{29}$ acumulado por casi cien años de nacionalismo que le llevarán a identificar «partido» y «país», organizándose más como un «movimiento-comunidad» ${ }^{30}$ debido a su fuerte implantación local, a su necesidad de movilización y al predominio de lo que C. Geertz llamó componentes "primordiales» ${ }^{31}$ y religiosos en su ideología. La necesi-

27 La relevancia de la dialécrica centro-periferia ya había sido resaltada por E. A. SHILs, que la formula en Center and Peripbery. Essays in Microsociology, Chicago: University Press, 1975. La dicotomía centro-periferia sitúa las variaciones étnicas en un modelo explicativo asociado al Nation-Building de autores como S. RokKAN, entre cuyos trabajos destacamos: «Nation-Building, Cleavage Formation and Structuring of Mass Politics», en S. RokKan (ed.), Citizens, Elections, Parties, Oslo: Universitetsforlaget, 1970, pp. 72-144; «Dimensions of State Formation and Nation-Building: A Posible Paradigm for Rescarch on variation within Europe», en C. Tilly (ed.), The Formation of National States in Western Europe, Princeton: Univ. Press, 1975, pp. 562-600, y Territorial Inequalities in Western Europe: Towards a Geoeconomic-geopolitical Model for the Explanation of Variations Regional Development, Bergen: INSS, 1978 (mimeo). A la vez, desde el modelo «inclusión/ exclusión» que ya señalara F. Barth en 1969 (en Los grupos étnicos y sus fronteras, México: FCE, 1976), el mantenimiento de las diferencias étnicas presupone que es más importante marcar las fronteras que definir lo que ellas incluyen, con lo que la demarcación territorial es tan significativa como las diferencias de comportamiento: véase S. RoKKAN y D. W. URwIN (eds.), The Politics of Territorial Identity, Londres: Sage, 1982; pero a la vez, como indica D. J. Grennwood y los acontecimientos nos demuestran, «la etnicidad es altamente maleable y sensible a las circunstancias en las que los grupos se encuentran a sí mismos», en "Continuity in Change: Spanish Basque Ethnicity as a Historical Process», en M. S. Esman (ed.), Ethnic Conflict in the Western World, Ithaca, NY: Cornell Univ. Press, 1977, p. 101

${ }^{2 *}$ A. P. Collen, The Symbolic Construction of Community, Nucva York: Tavistock, 1985, pp. 98 y ss.

${ }_{29}$ J. Corcuera, Orígcnes, ideología y organización del nacionalismo vasco, 1876-1904, Madrid: Siglo XXI, 1979; A. ElorzA, «La herencia sabiniana hasta 1936», en Colectivo, Nacionalismo y socialismo en Euskadi, Bilbao: IPES, 1984; G. Morán, Los españoles qui dejaron de serlo: Euskudi, 1937-1981, Barcelona: Planeta, 1982; A. PÉrez Agote, La reproducción del nacionalismo: el caso vasco, Madrid: CIS, 1984; A. Gurrutxaga, El código nacionalista durante el franquismo, Barcelona: Anthropos, 1985, y K. Sansebastí́n, Historiat del PNV, San Sebastián: Txertoa, 1984.

33 I. Corcuera y M. A. García Herrera se refieren al PNV como «partido-comunidad», en "Sistema de partidos, instituciones y comunidad nacionalista en Euskadi», en Revista de Politica Comparada, núm. 2 (1980), pp. 158 y ss.

"El iniciador del concepto de "primordialismo" es C. GeERTZ, «The Integrative Revolution: Primordial Sentiments and Civil Politics in the New States», en E. A. ShrLs y C. Geertz (eds.), Old Socicties and New States: The Quest of Modernity in Asia and Africa, Nueva York: Free Press, 1963, p. 109; E. Allard desarrollará el concepto en 
dad de articular un espacio en el seno de la política competitiva de los partidos de masas, el crecimiento experimentado en los primeros años de la transición y el poder omnímodo ejercido en las instituciones vascas desde 1979 hacen del PNV un partido de las características.apuntadas por O. Kirchheimer en la definición de los catch-all ${ }^{32}$ o «partidos caza todo».

Probablemente, el indicador más inmediato de tal contraposición de universos simbólicos sea la definición que los electorados hacen de su identidad básica vasca/española, tal como muestra la tabla 4, tomada del estudio IPV 87.

\section{TABLA 4}

Identidad de base según los electorados de las Autonómicas de 1986 en la $C A V$

\begin{tabular}{|c|c|c|c|c|c|c|c|c|}
\hline & $A P$ & $C D S$ & $E A$ & $E E$ & $H B$ & $P N V$ & PSOE & $N$ \\
\hline Sólo españoles $\ldots . . . . .$. & 22 & 34 & 1 & 1 & - & 2 & 18 & 6 \\
\hline Más españoles .......... & 21 & 7 & - & 1 & - & 2 & 18 & 4 \\
\hline $\begin{array}{llllll}\text { Igual } & \ldots & \ldots & \ldots & \ldots & \ldots\end{array}$ & 51 & 38 & 12 & 21 & 2 & 18 & 50 & 24 \\
\hline Más vascos . . . . . . . . . & 6 & 13 & 28 & 46 & 16 & 32 & 11 & 25 \\
\hline Sólo vascos $\ldots \ldots \ldots \ldots$ & - & - & 57 & 27 & 78 & 42 & - & 34 \\
\hline NS/NC $\ldots \ldots \ldots \ldots$ & - & 8 & 2 & 4 & 4 & 4 & 3 & 7 \\
\hline$\% \ldots \ldots \ldots$ & 100 & 100 & 100 & 100 & 100 & 100 & 100 & 100 \\
\hline $\begin{array}{lllllll}N & \ldots & \ldots & \ldots & \ldots & \ldots\end{array}$ & 78 & 59 & 469 & 566 & 665 & 869 & 502 & 4.975 \\
\hline
\end{tabular}

Fuente: F. J. Llera, IPV 87.

Si el exclusivismo vasco predomina en los electorados de HB (78 por 100) y EA (57 por 100), situándose los del PNV (42 por 100) ligeramente por encima del promedio y EE por debajo (27 por 100), el españolismo a ultranza se deja sentir relativamente más entre los electorados del CDS (34 por 100), AP (22 por 100) y PSOE (18 por 100$)$.

Implications of the Etbnic Revival in Modern Industrialized Society: A Comparative Study of Linguistic Minorities in Western Europe, Helsinki: Societas Scientiarum Fennica, 1979. Para J. Linz, el nacionalismo o los nacionalistas definirían la «comunidad étnica» o la «nación» basándola en «los elementos primordiales» y en los «voluntaristas»; véase "From Primordialism to Nationalism», en E. A. Tyryakian y R. Rogoswki (eds.), New Nacionalism of the Developped West: Toward Explanation, Hemel Hempstead: George Allen and Unwin, 1983, pp. 203-253.

${ }^{32}$ La adaptación del viejo partido-movimiento a las necesidades de la sociedad urbana, especialmente en su ambigüedad ideológica, encaja con la definición de O. Kirch-Heimer, "The Transformation of Western European Party Systems», en J. Lapalombara y M. Weiner (eds.), Political parties..., op. cit., pp. 177-200. Una evaluación reciente de este modelo la hace K. Ditrrich, "Testing the Catch-All Thesis: Some Difficulties and Possibilities», en H. DaAlder y P. MaIr (eds.), Western European..., op. cit., pp. 257.266. 
Por contra, la compatibilidad de identidades desde el predominio de lo vasco es lo que define el electorado de EE (67 por 100) y, en menor medida, al PNV (50 por 100), frente a la misma compatibilidad con predominio de lo español en los electorados de los partidos estatales.

En cuanto a las condiciones necesarias para que una persona pueda considerarse vasca se dibuja el siguiente cuadro (tabla 5), en el que el nacionalismo impone sus referencias, definiendo una ciudadanía diferencial en función de la adhesión a determinadas categorías de su universo simbólico.

\section{TABLA 5}

Condiciones necesarias para considerarse vasco ( $G V$ 87)

1. La voluntad de ser vasco:

SI $(89 \%)$ : todos los electores por encima del $80 \%$.

$\mathrm{NO}(8 \%)$.

2. La defensa de la nación vasca:

SI $(72 \%): \mathrm{HB} / \mathrm{EA} / \mathrm{PNV} / \mathrm{CDS} / \mathrm{EE}(>70 \%)-\operatorname{PSOE}(50 \%)$.

$\operatorname{NO}(22 \%)$ : AP $(67 \%)$ - PSOE $(41 \%)$.

3. Vivir en Euskadi:

SI $(39 \%)$ : CDS $(59 \%)$.

NO $(59 \%): \operatorname{AP}(86 \%)-\mathrm{EE} / \mathrm{EA}(60 \%)-\mathrm{PNV} / \mathrm{PSOE} / \mathrm{HB}(>50 \%)$

4. Hablar euskera:

$\operatorname{SI}(37 \%)$ : EA $(52 \%)-\operatorname{CDS}(50 \%) \cdot \operatorname{PNV}(41 \%)-\mathrm{HB}(38 \%)-\operatorname{PSOE}(33 \%)$

NO $(60 \%)$ : AP $(86 \%)$ - EE $(75 \%)$ - PSOE y HB $(>60 \%)-\operatorname{PNV}(55 \%)$ $\operatorname{CDS}(49 \%)-\mathrm{EA}(44 \%)$.

5. Descender de una familia vasca:

$\operatorname{SI}(30 \%): \operatorname{AP}(67 \%)-\operatorname{CDS}(37 \%)-\operatorname{EA~y~PNV~}(34 \%)$

$\mathrm{NO}(67 \%)$ : HB y EE $(>70 \%) \cdot \mathrm{CDS} / \mathrm{PNV} / \mathrm{PSOE} / \mathrm{EA}(>60 \%)$.

Desde otro punto de vista, la posición de los electorados respecto a las tres principales características que mejor definen la esencia de lo que se entiende por «lo vasco» vuelve a definirnos tal diferenciación, si bien con un cierto agrupamiento:

Grupo 1. CDS: la historia (33 por 100), el folklore (25 por 100) y el euskera (13 por 100).

AP: la historia (26 por 100 ), el euskera (26 por 100) y el nacionalismo (26 por 100$)$. 
Grupo 2. PSOE: la forma de ser (24 por 100), el euskera (18 por 100) y el nacionalismo (18 por 100$)$.

EE: la forma de ser (25 por 100), el euskera ( 22 por 100$)$ y el nacionalismo (19 por 100$)$.

Grupo 3. PNV: el euskera (28 por 100), el nacionalismo (25 por 100) y la forma de ser (19 por 100).

HB: el euskera (28 por 100), el nacionalismo (23 por 100) y la forma de ser (19 por 100).

Grupo 4. EA: la forma de ser (33 por 100), el nacionalismo (23 por 100) y el euskera (22 por 100).

El uso o no del euskera en la vida cotidiana, además de diferenciar muchos comportamientos y opiniones como una variable interviniente más, precisamente por su sobrevaloración simbólica, categoriza a los distintos electorados como muestra la siguiente tabla 6 , así: el distanciamiento de los electorados de los partidos de ámbito estatal, el mayor nivel de euskaldunización del nacionalismo tradicional, así como la movilización de la izquierda abertzale.

\section{TABLA 6}

Posición ante el euskera de los distintos electores en las elecciones autonómicas de 1986 en la CAV

\begin{tabular}{|c|c|c|c|c|c|c|c|c|}
\hline & $N$ & $A P$ & $C D S$ & PSOE & $P N V$ & $E A$ & $E E$ & $H B$ \\
\hline No interesa $\ldots \begin{array}{lll}\ldots & \ldots & \ldots\end{array}$ & 15 & 33 & 39 & 35 & 7 & 9 & 6 & 2 \\
\hline $\begin{array}{lllll}\text { Interesa } & \ldots & \ldots & \ldots & \ldots\end{array}$ & 30 & 24 & 29 & 35 & 34 & 25 & 38 & 28 \\
\hline $\mathrm{Ha}$ intentado $\ldots \ldots \ldots$ & 5 & - & - & 4 & 8 & 6 & 3 & 6 \\
\hline Aprende $\quad \ldots \quad \ldots \quad \ldots \quad \ldots$ & 8 & 4 & - & 4 & 2 & 6 & 16 & 12 \\
\hline $\begin{array}{lllll}\text { Entiende } & \ldots & \ldots & \ldots & \ldots\end{array}$ & 11 & 19 & - & 5 & 15 & 10 & 14 & 16 \\
\hline $\begin{array}{cccccc}\text { Habla } & \ldots & \ldots & \ldots & \ldots & \ldots\end{array}$ & 25 & 13 & 23 & 9 & 29 & 36 & 18 & 33 \\
\hline$\% \ldots \ldots \ldots$ & 100 & 100 & 100 & 100 & 100 & 100 & 100 & 100 \\
\hline
\end{tabular}

Fuente: F. J. Llera, IPV 87.

Aunque la mayoría de los encuestados (62 por 100) se inclina a favor de una enseñanza bilingüe - especialmente entre los votantes de AP ( 86 por 100), EE (72 por 100), PSOE, PNV y EA (69 por 100)-, la demanda de que toda la enseñanza sea en euskera alcanza cotas importantes entre las que se consideran sólo vascos (38 por 100), los que hablan euskera (37 por 100), 
los votantes de HB ( 36 por 100 ), los que se sienten nacionalistas ( 28 por 100 ) y los votantes de EA (23 por 100).

Por orro lado, la mayoría de los entrevistados (58 por 100) rechaza la valoración prioritaria del euskera para el acceso a un puesto de trabajo: opinión predominante en los electorados menos euskaldunizados, como los de AP (100 por 100$)$, PSOE ( 80 por 100$)$, CDS (78 por 100) y EE (67 por 100). Sin embargo, esta tendencia de rechazo general se convierte en aceptación entre los euskaldunes (68 por 100), los que se consideran sólo vascos (62 por 100), los independentistas (61 por 100), los lectores de Deia (59 por 100) y Egin (57 por 100), los que se sienten nacionalistas (55 por 100) y los votantes de HB (58 por 100), EA (52 por 100) y PNV (51 por 100).

El rechazo mayoritario se incrementa (61 por 100) cuando se plantea la hipótesis de que el euskera sea la única lengua oficial del País Vasco, manteniéndose las mismas pautas de diferenciación sociopolítica anterior, si bien ahora los electorados del PNV y EA se dividen en dos grupos opuestos.

\section{LOS VIOLENTOS: ALGO MAS QUE CONVIDADOS DE PIEDRA}

La radicalidad del problema vasco estriba en la dualidad del conflicto simbólico sobre el «nosotros» y su objetivación política, pero en un prolongado contexto histórico de violencia, interiorizada y experimentada por las sucesivas generaciones como física y simbólica. A su vez, el causante de tal violencia, si para unos fue el franquismo o la Dictadura, para otros es, simplemente, el Estado, al que se le disputa la legitimidad de su monopolio de la violencia, pero al que se le añade la cualidad simbólica de «español» como sinónimo de «extranjero».

Lengua y ocupación van a erigirse en los pilares fundamentales de una nueva centralidad simbólica en construcción, basada en el sentido agónico y trágico de una acción nacionalista, cuya carencia de fuerte configuración ideológica o programática no será óbice para poner en marcha penetrantes y eficaces mecanismos de inclusión/exclusión comunitaria ${ }^{33}$.

El fracaso relativo de la integración estatonacional española tiene mucho que ver con la forma militarizada en que se desarrolla la homogeneización administrativa y territorial del Estado ${ }^{34}$.

${ }^{33}$ Cfr. F. Barth, op. cit., y, también, R. Nisber, The quest for Communily, Nueva York: Oxford Univ. Press, 1975. 1980.

${ }^{4}$ Cfr. J. Beneyto, Las autonomias. El poder regional en España, Madrid: Siglo XXI, 
La preocupación central de esta reflexión es la comprensión de los mecanismos sociales por los que la violencia sigue siendo un actor privilegiado del drama social vasco después de casi dos siglos ${ }^{35}$.

Donde haya un problema en la definición social del «nosotros» existirá crisis de legitimación del Estado y, por consiguiente, de su monopolio de la violencia, con lo que tal crisis no se planteará sólo en el terreno valorativo o normativo, sino, y sobre todo, en el simbólico. El conflicto sobre el «nosotros» y su objetivación política indica que no existe un único universo simbólico de orientación de la acción con evidencia social compartida.

La amarga y prolongada experiencia de la represión franquista de posguerra tiene en el País Vasco una extensión y una violencia especiales, pero, sobre todo, es percibida por el mundo nacionalista como una victoria militar de lo estatal español sobre Euskadi ${ }^{36}$. De este modo, convergen la consideración que de Euskadi como país ocupado tenía el nacionalismo aranista y la interiorización del franquismo como realización de dicha ocupación ${ }^{37}$.

Las nuevas generaciones de vascos han interiorizado y reformulado una particular herencia, cual es la respuesta violenta a la violencia física y simbólica ejercida desde y por el Estado contra el conflicto de identidades contenido en el código nacionalista formulado por S. Arana y el Partido Naciolista Vasco ${ }^{38}$.

Si a la memoria histórica de guerra y violencia acumuladas durante ciento cincuenta años añadimos ahora la inmediata experiencia biográfica de la represión, en su más amplio espectro y de forma indiscriminada, concentrada sobre un territorio de «excepción», tenemos sentadas las bases tanto para la ruptura generacional ${ }^{39}$ como para el arraigo social de una adhesión afectiva colectiva a la violencia ${ }^{40}$.

Por consiguiente, el proceso de socialización de las nuevas generaciones coincide con un ambiente de sobrevaloración simbólica de todas las expresiones de lo vasco, especialmente la lengua, junto con la movilización unitaria de la solidaridad frente a la represión generalizada e indiscriminada de los últimos años de un franquismo decadente, lo que va a sublimar más, si cabe, el componente militarista de ETA en detrimento de sus otras tendencias más ideológicas o racionalizadoras políticamente.

Por otro lado, los desajustes estructurales y la profundidad de la crisis industrial vasca están haciendo aparecer un fenómeno nuevo, como es la

${ }^{35}$ Es la reflexión de $J$. Caro en El laberinto vasco, San Sebastián: Txertoa, 1984, pp. 96 y ss.

${ }_{36}$ Cfr. G. Morán, Los españoles..., op. cit.

${ }^{37} \mathrm{Cfr} . \mathrm{G}$. Jáuregur, Ideología y estrategia politica de ETA, Madrid: Siglo XXI, 1981.

${ }^{38}$ Cfr. J. Corcuera, Orígenes, ideología y organización del nacionalismo vasco, 1876 1904, Madrid: Siglo XXI, 1979.

${ }_{39}$ Este proceso lo sistematiza A. Ferrand en su «Ritualisation du rapoprt entre les ages», en M. MafFessoli y A. Bruston (eds.), Violence et Trasgression, París: Anthropos, 1979 , pp. 151-163.

${ }^{40}$ M. Maffessoli, «La violence au le désir du collectif», en op. cit., pp. 171 y ss. 
emergencia desde la periferia social de distintas respuestas subculturales, resultantes de estados de anomía y conflicto que encuentran un efecto multiplicador en la desorganización social y en la relevancia adquirida por la transgresión social en el trásito de la Dictadura a la Democracia.

\subsection{La espiral del silencio}

E. Noelle-Neuman ha denominado «espiral del silencio» ${ }^{41}$ al mecanismo social que se desencadena, al estigmatizarse la exteriorización de una identidad o comportamiento político, por lo que éste se ve obligado a silenciarse y, al no oírse, se bloquean las posibilidades de su reproducción social. Ya J. Linz hizo referencia a esta realidad al comprobar empíricamente la existencia de miedo en la sociedad vasca para participar activamente en la política en $1979^{42}$.

Los que realizamos encuestas en el País Vasco sabemos lo que esto supone de sesgo de las opciones políticas estatales y de derecha, por ejemplo. En nuestro estudio de GV 87 les preguntamos a los entrevistados si se sentían libres para hablar de política, resultando que sólo cuatro de cada diez ciudadanos manifiestan hacerlo libremente con todo el mundo, especialmente entre los nacionalistas de EA (61 por 100) y EE (58 por 100) y, en menor medida, HB (45 por 100) y PNV (41 por 100).

Por otro lado, otro tanto dicen sentir esa libertad sólo en su círculo más próximo y de confianza, experiencia que sobresale en los electorados de AP (67 por 100), HB (44 por 100), PSOE (42 por 100) y, algo menos, PNV y EE (40 por 100$)$.

Finalmente, un 14 por 100 expresa su imposibilidad para hablar de politica con nadie o casi nadie, algo que se deja sentir con más intensidad en los electorados del CDS (33 por 100) y PSOE (24 por 100).

Aunque existe una multidimensionalidad del miedo y el control social, éste denota una segmentación política importante que afecta especialmente a las opciones estatales.

\subsection{La imagen de ETA}

En el estudio de la valoración de las instituciones y en el discurso nacionalista están, explícita o implícitamente, el rechazo antirrepresivo de lo estatal, por un lado, y de la imposición cultural y política ejercida por el centralismo español, por el otro, quedando bastante claro que ambas violencias, la física y la simbólica, constituyen el núcleo deslegitimador de lo estatal

"E. Noelle-Neumann, Die Schweigespirale. Offentliche Meinungusere soziale Haut, Munich: Piper, 1980.

${ }^{42}$ J. Linz, Conflicto..., op. cit., p. 18. 
desde el nacionalismo vasco. Sabido es, también, que una parte de ese fondo deslegitimador ha sido transferida, en forma de resistencia legitimada, a la violencia política ejercida por ETA durante años, constituyendo ésta, su personal, su acción y su discurso, el centro simbólico de una subcultura política antisistema organizada y reproducida por $\mathrm{HB}$ y los organismos que conforman el llamado «bloque KAS».

Del estudio 1.729 del CIS sobre los etarras (a partir de 1.377 entrevistas en el País Vasco y Navarra), donde se les pregunta a los entrevistados que opten entre dos frases que polarizan las opiniones positivas y negativas sobre aquéllos, resulta la tabla 7 , de la que se deducen tres tipos de comportamientos bastante diferenciados: por un lado, la opción casi unánime de HB ( 81 por 100) por el calificativo de «idealistas y luchadores por la libertad»; en segundo lugar, el desconcierto y las dificultades de definición de los electorados nacionalistas moderados de EA, EE y, en menor medida, del PNV; finalmente, la rotunda inclinación de los electorados de ámbito estatal por los calificativos de «terroristas y delincuentes desalmados».

\section{TABLA 7}

Opinión sobre los bombres de ETA según los electorados autonómicos de 1986 en el País Vasco

\begin{tabular}{|c|c|c|c|c|c|c|c|c|}
\hline & $N$ & $A P$ & CDS & PSOE & PNV & $E A$ & $E E$ & $H B$ \\
\hline Terroristas $\ldots \ldots \ldots \ldots$ & 39 & 91 & 81 & 75 & 40 & 34 & 26 & — \\
\hline Idealistas $\ldots \ldots \ldots \ldots$ & 23 & - & - & 5 & 20 & 19 & 25 & 81 \\
\hline $\mathrm{NS} / \mathrm{NC} \ldots \ldots \ldots \ldots$ & 38 & 9 & 19 & 20 & 40 & 47 & 49 & 19 \\
\hline$\%$ & 100 & 100 & 100 & 100 & 100 & 100 & 100 & 100 \\
\hline
\end{tabular}

FUENTE: CIS, núm. 1729.

Si se comparan estos datos con los aportados por J. Linz en $1979^{43}$, además de comprobarse la pérdida de imagen positiva y de respaldo social por parte de los etarras en el conjunto de la opinión pública, se constatan los siguientes procesos: primero, una decantación de los electorados estatales, sobre todo el socialista, que los consideraba mayoritariamente (46 por 100) «patriotas e idealistas»; segundo, una pérdida de apoyo entre el PNV (40 por 100) y, sobre todo, EE ( 85 por 100); tercero, una estabilidad del respaldo de HB ( 85 por 100$)$.

De nuestro estudio IPV 87 se deduce que, si bien el tejido social es permeable al apoyo, más o menos incondicional o matizado, a ETA, éste se

${ }^{43}$ Ibid., p. 639. 
deja sentir relativamente más entre los más jóvenes (12 por 100) y, obviamente en el electorado de $\mathrm{HB}$, cuya distribución es sintomática, así: si un 3 por 100 manifiesta su apoyo total, un 35 por 100 está básicamente de acuerdo, aunque reconozca errores, otro 32 por 100 acepta sus fines pero rechaza sus métodos violentos, otro 22 por 100 no justifica su opinión y otro 8 por 100 se pronuncia con distintos matices de rechazo.

El apoyo a los fines y el rechazo de los métodos sobresale, relativamente, entre los entrevistados con estudios universitarios (18 por 100) y entre los menores de veinticinco años (20 por 100$)$, a la vez que en el electorado de HB (32 por 100).

La justificación remota («antes estaba justificada, pero en democracia ya no tiene sentido») destaca entre los que tienen estudios superiores (27 por 100) y universitarios (24 por 100) y los electorados nacionalistas moderados: EE (40 por 100), EA (38 por 100$)$ y PNV (30 por 100$)$.

Finalmente, el rechazo más o menos frontal se acentúa entre la población sin estudios (44 por 100), los mayores de treinta y cinco años (40 por 100) y los electorados estatales: AP ( 79 por 100), CDS ( 75 por 100), PSOE (66 por 100), en menor medida, el PNV (39 por 100).

\subsection{La subcultura de la violencia}

La permeabilidad del discurso de los violentos parte de la dualidad de centralidades simbólicas y se asienta en la heterogeneidad de los soportes sociales propiciados por la fragmentación política; por otro lado, la desconfianza respecto del centralismo y la imagen represiva del Estado, así como la solidaridad interna de la comunidad nacionalista, articulan una subcultura política en la que se comparten los argumentos de los violentos más allá del apoyo explícito que se les pueda prestar.

Asistimos estos meses, y más estos días, a un debate político sobre la necesidad de la pacificación y de la movilización de la sociedad contra la violencia con el telón de fondo de las conversaciones entre ETA y el Gobierno central en Argel, por un lado, y la maximización de todo el aparato organizativo y propagandístico de los que apoyan logísticamente a los violentos, por el otro.

Entre las cuestiones que se debaten, sobre todo en el mundo nacionalista, destacan el carácter de la propia negociación y los contenidos de la misma: la alternativa KAS (básicamente: amnistía, sustitución de las Fuerzas de Seguridad del Estado, integración de Navarra y reconocimiento del Derecho de Autodeterminación).

De nuestro estudio IPV 87 se deduce que tan sólo seis de cada diez electores de $\mathrm{HB}$ creen en ella, llegando a casi un 30 por 100 los que se muestran indiferentes o no tienen opinión al respecto y otro 11 por 100 que se ma- 
nifiesta abiertamente en contra de su utilidad y prioridad. Vuelve a ser, por tanto, un punto débil de la argumentación de HB, que es susceptible de desgaste especialmente si se la liga a la cuestión de la negociación.

Si los electorados mayoritarios del PNV, PSOE, EA y CDS se caracterizan por su mayoritaria indiferencia o falta de opinión, entre los de AP (57 por 100) y EE (43 por 100) destaca relativamente el recházo.

El Gobierno del Estado y la mayoría de las fuerzas políticas representadas, tanto en el Parlamento español como en el vasco, niegan la posibilidad de incluir contenidos políticos en una eventual negociación con ETA, mientras que ésta plantea exigencias estrictamente políticas en su «alternativa KAS». La opinión pública, sin embargo, no parece alcanzar a ver los perfiles que diferencian ambas opciones.

Sin plantear tal diferenciación, en nuestro estudio GV 87 les hemos preguntado a los entrevistados sobre la inclusión o no en esa negociación de la mayoría de los contenidos de la alternativa KAS, sin mencionarla (véase tabla 8).

Cuatro fenómenos aparecen claros: por un lado, la no ruptura radical entre el discurso antisistema y el resto de la familia nacionalista; por otro lado, la ausencia de una confrontación radical entre los mundos nacionalista y no nacionalista; en tercer lugar, la extensión de un cierto fatalismo en el conjunto de la sociedad vasca; y, finalmente, la aparición de una actitud de desistimiento en buena parte de los sectores no nacionalistas.

No necesita comentario el esfuerzo que van a tener que desarrollar los políticos vascos para convencer a sus respectivas bases de la ilegitimidad de ETA para representar aspiraciones, más o menos, generales de la población vasca ante el Gobierno central. El hecho de que la mayoría de todos los electorados nacionalistas y del conjunto de la población, aunque sea con intensidades distintas, y que hasta el electorado no nacionalista, en general, y más particularmente el del PSOE, se muestren divididos, plantea una dificultad seria a cualquier estrategia de movilización de la opinión pública contra la violencia desde las instituciones.

El éxito de la subcultura de la violencia política tiene un doble componente: de un lado, producir el desistimiento de la mayor parte de los sectores sociales con tal de acabar con las consecuencias de la barbarie y, de otro, interiorizar que la salida es una negociación a cualquier precio. Esto convierte en evidencia social y hace plausible que la misma tiene una rentabilidad política concreta más allá de la simple desactivación de la violencia, lo que legitima de forma indirecta tal estrategia para la obtención de fines políticos, dejando en un difícil papel a las instituciones y a la clase política democráticas. 


\section{TABLA 8}

Contenidos de una negociación con ETA seguin identidad nacionalista y electorados en 1986

\begin{tabular}{|c|c|c|c|c|c|c|c|c|c|c|c|c|c|c|c|c|}
\hline & \multicolumn{2}{|c|}{$\begin{array}{l}\text { Nacio- } \\
\text { nalistas }\end{array}$} & \multicolumn{2}{|c|}{$\begin{array}{l}\text { No nacio- } \\
\text { nalistas }\end{array}$} & \multicolumn{2}{|c|}{$H B$} & \multicolumn{2}{|c|}{$E A$} & \multicolumn{2}{|c|}{$P N V$} & \multicolumn{2}{|c|}{$E E$} & \multicolumn{2}{|c|}{ PSOE } & \multicolumn{2}{|c|}{$N$} \\
\hline & $S_{i}^{\prime}$ & No & $S_{i}^{\prime}$ & No & Si & No & Si & No & $S_{i}$ & No & Si & No & Si & No & $S i$ & No \\
\hline 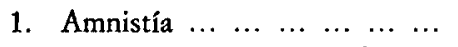 & 67 & 16 & 31 & 41 & 86 & 7 & 59 & 26 & 49 & 32 & 52 & 33 & 18 & 54 & 49 & 27 \\
\hline $\begin{array}{l}\text { 2. Sustitución Fuerzas de Seguri- } \\
\text { dad } \ldots \begin{array}{ccccccc}\ldots & \ldots & \ldots & \ldots & \ldots & \ldots & \ldots\end{array} \ldots\end{array}$ & 76 & 11 & 42 & 27 & 90 & 4 & 74 & 14 & 69 & 15 & 72 & 18 & 29 & 40 & 59 & 17 \\
\hline 3. Integración de Navarra ...... & 78 & 9 & 34 & 31 & 89 & 6 & 77 & 13 & 72 & 13 & 56 & 28 & 33 & 37 & 57 & 18 \\
\hline $\begin{array}{l}\text { 4. Referéndum por la autodeter- } \\
\text { minación } \ldots \ldots \ldots c c c c \\
\ldots\end{array}$ & 78 & 8 & 47 & 23 & 90 & 4 & 81 & 8 & 67 & 14 & 77 & 16 & 38 & 32 & 63 & 14 \\
\hline
\end{tabular}

FuENTE: F. J. Llera, GV 87. 


\section{NACIONALISTAS Y NO NACIONALISTAS: DOS SUBCULTURAS QUE CONVIVEN EN UNA NACION POR CONSTRUIR}

Una nación moderna se construye a partir de la obtención de consensos, que no necesariamente unanimidades o uniformidades, sobre los componentes básicos que la identifican, la permiten organizarse y la reproducen en el tiempo, reduciendo al mínimo o marginalizando los niveles de impugnación desligitimadora. Este, por el momento, no es nuestro caso, como hemos podido cuantificar operativamente.

En Euskadi conviven, al menos, dos subculturas, que no dos comunidades. Una de ellas organizada en torno al capital simbólico nacionalista y dominante a la hora de definir los mecanismos de inclusión/exclusión en el seno de nuestra sociedad, si bien con una definición política de confrontación con el Estado, respecto del cual ha interiorizado su posición periférica y su minorización cultural. La otra, orientada por las pautas de la cultura nacional española y que se caracteriza por una mayor positividad respecto al mundo institucional, en general, y al entramado estatal, en particular, y que experimenta a la vez la dualidad de vivir en minoría en su propia sociedad vasca, aunque reforzada por la mayoría en la sociedad española.

Sin embargo, no parece que ambos centros orientadores de la acción política de los ciudadanos y de su identidad colectiva hayan llevado su contraposición simbólica de la mano de cierta clase política hasta el punto de abrir una brecha sociológica entre dos mundos incomunicados, sino que, por el contrario, parece que ambos se intercambian y comparten muchas opiniones $\mathrm{y}$ actitudes respecto de las cuestiones que les afectan como habitantes de Euskadi, lo que permite abrigar esperanzas sobre el progresivo avance de los perfiles pluralistas de una «cultura cívica» vasca.

Con todo, es cierto que se puede hablar y se pueden definir una mayor variedad de culturas partidarias, tal como hace R. Gunther, para el caso español ${ }^{44}$.

La estabilidad política del País Vasco va a depender del desarrollo de una cultura de élite con capacidad de negociación y de diálogo y del establecimiento de acuerdos que preserven los intereses y demandas de las distintas fuerzas sociales, en la línea del modelo consociacional de A. Lijphart ${ }^{45}$. Asimismo, la conjunción de fuerzas para la salida de la crisis económica, el papel de los grupos de interés en Euskadi, el pluralismo sindical, la diversidad de estructuras empresariales y financieras, la existencia del Consejo de Relaciones Laborales, la estructura fiscal de la foralidad y otra

${ }^{44}$ R. Gunther, Politics and Culture in Spain, Ann Arbor: Univ. of Michigan, 1988, pp. 26 y ss.

${ }_{43}$ A. Lijphart, The Politics of Accommodation, Berkeley, Ca.: Univ. of California Press, 1968. 
serie de plataformas de negociación hacen avanzar un cierto modelo neocorporativista $^{46}$ que habrá de articular un determinado modelo de política de consenso.

En este sentido, el necesario consenso que pueda fundamentar, además de una normalización política, una pérdida de centralidad e inmediatez de la violencia, sólo parece posible si la sociedad vasca tiene éxito en la construcción social de un centro simbólico catalizador de una identidad colectiva no discutible. Ahora bien, parece que, en el orden del «sentido» para los actores sociales, la expansión y predominio de los mecanismos de inclusión de la misma sólo es posible si se construye como una «identidad dinámica», utilizando palabras de J. Caro Baroja ${ }^{47}$.

45 Se pueden ver los modelos de P. Schmitter y G. Lenmbruch (eds.), Trends toward Corporatist Intermediation, Londres: Sage, 1979; también, H. Katzenstein, Small States and World Markets, Ithaca, NY: Cornell Univ. Press, 1985.

${ }^{47}$ J. Caro, El laberinto..., op. cit., pp. 11 y ss. 